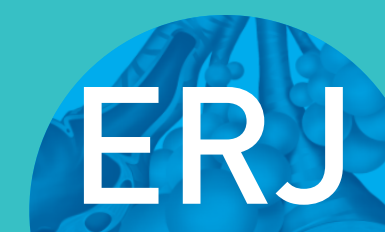

open research
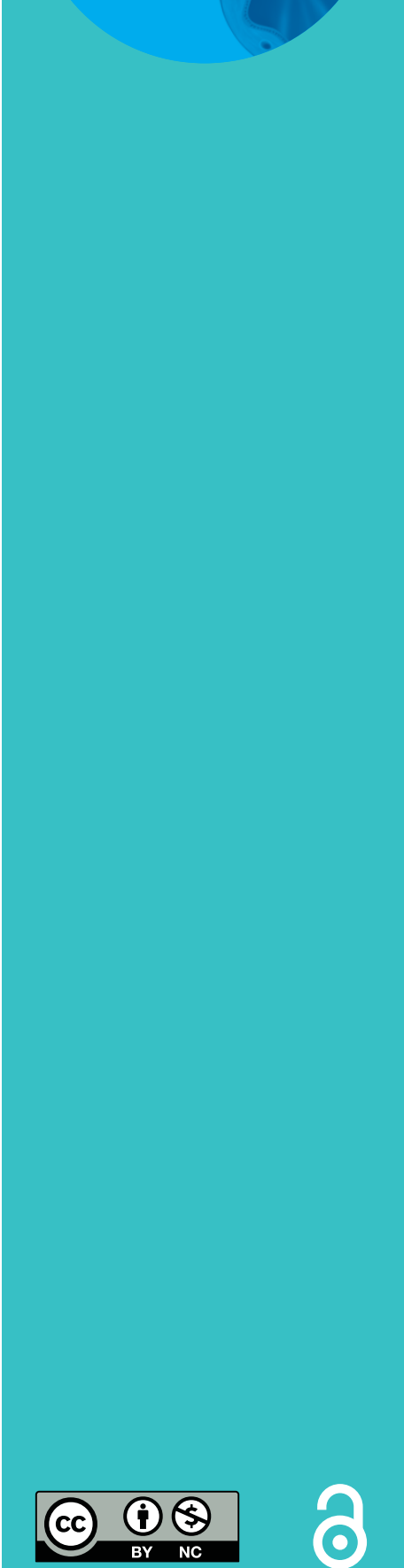

\section{Effects of bile acids on human airway epithelial cells: implications for aerodigestive diseases}

\author{
Adil Aldhahrani ${ }^{1}$, Bernard Verdon ${ }^{1}$, Chris Ward ${ }^{1,2,3}$ and Jeffery Pearson ${ }^{1,3}$
}

Affiliations: ${ }^{1}$ Institute for Cell and Molecular Biosciences, Newcastle University, Newcastle upon Tyne, UK. ${ }^{2}$ Institute of Cellular Medicine, Newcastle University, Newcastle upon Tyne, UK. ${ }^{3}$ These authors contributed equally.

Correspondence: Chris Ward, Institute for Cellular Medicine, The Medical School, University of Newcastle upon Tyne, Framlington Place, Newcastle upon Tyne NE2 4HH, UK. E-mail: chris.wardancl.ac.uk

ABSTRACT Gastro-oesophageal reflux and aspiration have been associated with chronic and end-stage lung disease and with allograft injury following lung transplantation. This raises the possibility that bile acids may cause lung injury by damaging airway epithelium. The aim of this study was to investigate the effect of bile acid challenge using the immortalised human bronchial epithelial cell line (BEAS-2B).

The immortalised human bronchial epithelial cell line (BEAS-2B) was cultured. A 48-h challenge evaluated the effect of individual primary and secondary bile acids. Post-challenge concentrations of interleukin (IL)-8, IL-6 and granulocyte-macrophage colony-stimulating factor were measured using commercial ELISA kits. The viability of the BEAS-2B cells was measured using CellTiter-Blue and MTT assays.

Lithocholic acid, deoxycholic acid, chenodeoxycholic acid and cholic acid were successfully used to stimulate cultured BEAS-2B cells at different concentrations. A concentration of lithocholic acid above $10 \mu \mathrm{mol} \cdot \mathrm{L}^{-1}$ causes cell death, whereas deoxycholic acid, chenodeoxycholic acid and cholic acid above $30 \mu \mathrm{mol} \cdot \mathrm{L}^{-1}$ was required for cell death. Challenge with bile acids at physiological levels also led to a significant increase in the release of IL-8 and IL6 from BEAS-2B.

Aspiration of bile acids could potentially cause cell damage, cell death and inflammation in vivo. This is relevant to an integrated gastrointestinal and lung physiological paradigm of chronic lung disease, where reflux and aspiration are described in both chronic lung diseases and allograft injury.

$@$ ERSpublications

Bile acid exposure has a significant effect on cytokine production which could contribute to airway injury http://ow.ly/Jwfa309jRqu

Cite this article as: Aldhahrani A, Verdon B, Ward C, et al. Effects of bile acids on human airway epithelial cells: implications for aerodigestive diseases. ERJ Open Res 2017; 3: 00107-2016 [https:// doi.org/10.1183/23120541.00107-2016].

Received: Sept 292016 | Accepted after revision: Feb 032016

Conflict of interest: None declared.

Copyright $\odot$ ERS 2017. This article is open access and distributed under the terms of the Creative Commons Attribution Non-Commercial Licence 4.0. 


\section{Introduction}

The airway epithelium plays a critical role in diseased as well as non-diseased lungs, primarily by providing a physical barrier to foreign particles such as particulates and smoke, as well as viruses and bacteria. In addition, it enables a range of pro-inflammatory, anti-microbial and regulatory functions. Epithelial regulatory functions can involve generating and disseminating a range of mediators for various responses, including chemotaxis, inflammatory cell differentiation and activation in both diseased and non-diseased conditions [1].

Many chronic degenerative diseases, including lung allograft dysfunction, are characterised by epithelial damage related to pro-inflammatory cytokines. This process commonly involves bronchial cell injury and necrosis, as well as leukocyte infiltration, leading to inflammatory lung disease [2].

When the lower oesophageal sphincter becomes relaxed, gastric contents may pass into the oesophagus by retrograde flow. Gastro-oesophageal reflux (GOR) is not uncommon and generally may not be harmful [3]. However, certain conditions may lead to GOR becoming pathological, resulting in gastro-oesophageal reflux disease (GORD) [1,2]. GORD symptoms can be relieved by proton pump inhibitors (PPIs). PPIs work by binding covalently to gastric $\mathrm{H}^{+} \mathrm{K}^{+}$-ATPase pumps, causing irreversible inhibition of the final step in gastric acid secretion. The use of PPIs therefore causes gastric $\mathrm{pH}$ to be elevated [4]. PPI treatment can reduce gastric acid secretion, but does not prevent overall gastric aspiration, which includes non-acid components [5]. This is one reason why acid suppression alone may not be entirely effective in preventing GOR [6], and in cases where symptoms are unresponsive to PPI treatment, it is thought that these continued symptoms may be caused by reflux of agents other than gastric acid [7].

Bile acids (BAs) are sparingly water-soluble steroids produced by hepatocytes. Despite being strongly cytotoxic and associated with gastrointestinal malignancy [8], BAs are an essential component of the digestive process, aiding lipid digestion in the small intestine. "Primary BAs" are synthesised by conversion of cholesterol into cholic acid (CA) and chenodeoxycholic acid (CDCA), which are then conjugated to glycine or taurine. These are deconjugated by bacterial enzyme action in the colon into "free BAs". The action of $7 \alpha$-dehydroxylase converts free BAs into "secondary BAs" (CDCA into lithocholic acid (LCA) and CA into deoxycholic acid (DCA)).

Gastric mucosa $[8,9]$, colonic mucosa $[9,10]$ and hepatocytes [11] are all affected by BAs. However, their toxicity to airway mucosa is less well understood [12]. Patients with a range of airway diseases have been shown to exhibit higher BA concentrations in their bronchoalveolar lavage (BAL) [13]. Gastric aspiration has been revealed to lead to severe pneumonitis [14]. Most therapeutic interventions for GORD and associated inflammatory disease have sought to inhibit acid production by gastric parietal cells. However, a study conducted by KAUER et al. [15] measured both acid (using standard pH tests) and duodenal juice (bilirubin monitoring) reflux in 53 GORD patients. Both types of reflux were found to be present in two-thirds of the patients. Furthermore, higher levels of bilirubin were identified in the refluxate of patients with Barrett's oesophagus. These findings may explain the limited success of PPI therapy in this setting and perhaps why some patients appear more prone to developing Barrett's oesophagus.

The most physiologically relevant cell type to evaluate airways damage is arguably the primary human bronchial epithelial cell (PBEC), but these cells are costly and difficult to culture [16]. Consequently, cell lines have been investigated regarding their ability to provide a useful model to complement the use of PBECs. The human bronchial epithelial cell line, BEAS-2B, for example, is able to secrete interleukin (IL)-6, IL-8 and other cytokines, while maintaining epithelial cell morphology in vitro. These qualities make BEAS-2B a favoured cell line for airway epithelial structure and functional studies [17].

This study hypothesised that BAs, described previously as being present in the lung, can cause damage to the airway epithelium, which may be a mechanism for lung injury. The study aimed to establish a model for airway epithelial cell injury that is relevant to reflux-associated chronic degenerative airways diseases. BEAS-2B cells were challenged with primary and secondary Bas, and pro-inflammatory cytokine levels (IL-8, IL-6 and granulocyte-macrophage colony-stimulating factor (GM-CSF)) were measured by ELISA. These cytokine markers were chosen on the basis of prior studies, which have found these factors to be released by damaged cells, and because they are associated with airway pathophysiology [17].

\section{Materials and methods \\ Cell culture \\ BEAS-2B culture}

BEAS-2B (obtained from ATCC; LGC Standards, Teddington, UK) is a human bronchial epithelial cell line derived from normal human epithelial cells immortalised using a hybrid of adenovirus 12 and simian virus 40 [18]. BEAS-2B cells were seeded in 24 -well plates at a density of 6 to $7 \times 10^{5}$ cells $\cdot \mathrm{mL}^{-1}$ and were grown in $500 \mu \mathrm{L}$ bronchial epithelial growth medium (BEGM) (Lonza, Cambridge, MA, USA) at $5 \% \mathrm{CO}_{2}$ 
and $37^{\circ} \mathrm{C}$. This was supplemented with $2 \mathrm{~mL}$ bovine pituitary extract $\left(0.004 \mathrm{~mL} \cdot \mathrm{mL}^{-1}\right), 0.5 \mathrm{~mL}$ insulin $\left(5 \mu \mathrm{g} \cdot \mathrm{mL}^{-1}\right), 0.5 \mathrm{~mL}$ hydrocortisone $\left(0.5 \mu \mathrm{g} \cdot \mathrm{mL}^{-1}\right), 0.5 \mathrm{~mL}$ retinoic acid $\left(0.1 \mathrm{ng} \cdot \mathrm{mL}^{-1}\right), 0.5 \mathrm{~mL}$ transferrin $\left(10 \mu \mathrm{g} \cdot \mathrm{mL}^{-1}\right), \quad 0.5 \mathrm{~mL}$ tri-iodothyronine $\left(6.7 \mathrm{ng} \cdot \mathrm{mL}^{-1}\right), \quad 0.5 \mathrm{~mL}$ adrenaline $\left(0.5 \mu \mathrm{g} \cdot \mathrm{mL}^{-1}\right), \quad 0.5 \mathrm{~mL}$ recombinant epidermal growth factor human $\left(10 \mathrm{ng} \cdot \mathrm{mL}^{-1}\right), 100 \mathrm{U} \cdot \mathrm{mL}^{-1} \mathrm{~L}$-glutamine and $100 \mathrm{U} \cdot \mathrm{mL}^{-1}$ penicillin/streptomycin (Sigma, Gillingham, UK).

\section{BEAS-2B cell stimulation}

At about $80 \%$ confluence, BEAS-2B cells were rested for $24 \mathrm{~h}$ in serum-free medium (BEBM, $50 \mathrm{mg} \cdot \mathrm{mL}^{-1}$ gentamycin, $50 \mu \mathrm{g} \cdot \mathrm{mL}^{-1}$ amphotericin B (Lonza), $100 \mathrm{U} \cdot \mathrm{mL}^{-1}$ penicillin, $100 \mu \mathrm{g} \cdot \mathrm{mL}^{-1}$ streptomycin (Sigma). BAs were dissolved in methanol to prepare stock solutions $\left(100 \mathrm{Mmol} \cdot \mathrm{L}^{-1}\right)$. The solution was diluted with resting medium to achieve a range of experimental concentrations. A total of three experiments with five replicate wells $(n=15)$ were conducted. The following BA concentrations were used: $1,5,10,15$, $20,30,50,75$ and $100 \mu \mathrm{mol} \cdot \mathrm{L}^{-1}$. After $48 \mathrm{~h}$ incubation, cell culture supernatants were collected to measure cytokine concentrations. Commercial IL-8, IL-6 and GM-CSF ELISA kits were used (R\&D Systems, Abingdon, UK).

\section{Cell viability assays}

CellTiter-Blue assay

Cell viability was assessed using the CellTiter-Blue assay (Promega, Madison, WI, USA). Known ratios of living to dead cells were used to generate a standard curve (with the dead cell control prepared by exposure to ice-cold methanol for $5 \mathrm{~min}$ ) and to provide cell mixtures. The standard curve comprised $100 \%$ live cells (resting media); 25/75\%, 50/50\%, 75/25\% dead/live cells; and 100\% dead cells. This was used to determine the percentages of viable cells. Wavelengths of 560 and $600 \mathrm{~nm}$ were used to measure absorbance and determine signal strength.

\section{Thiazolyl blue tetrazolium bromide}

The MTT (Sigma, St Louis, MO, USA) assay, which measures mitochondrial function, was used for several experiments. For the MTT assay, cells were cultured and stimulated with BAs. After $48 \mathrm{~h}$, the medium was removed and replaced with $100 \mu \mathrm{L}$ MTT solution $\left(5 \mathrm{mg} \cdot \mathrm{mL}^{-1}\right.$ in $3 \mathrm{~mL}$ of fresh medium without BAs). The plate was incubated for a further $4 \mathrm{~h}$ at $37^{\circ} \mathrm{C}$. Formazan crystals developed, and were dissolved in MTT solubilisation solution equal to the original culture medium volume. A gyratory shaker was used to accelerate dissolution. The standard curve comprised 100\% live cells (resting media); 25/75\%; 50/50\%; 75/25\% dead/live cells; and $100 \%$ dead cells. This was used to determine the percentages of viable cells. Spectrophotometric analysis, with reference and background wavelengths of 570 and $690 \mathrm{~nm}$, was used to measure well absorbance.

\section{Statistical analysis}

Analyses were performed using GraphPad Prism v6 for Windows. All data are represented as mean \pm SEM and $\mathrm{n}$ indicates the number of repeat experiments performed. For experiments involving comparison of three or more matched groups, repeated measures ANOVA was used followed by the Bonferroni post hoc test, which compares all pairs of groups. In line with convention, p-values of $\leqslant 0.05$ were considered significant.

\section{Results}

\section{Effect of BA on BEAS-2B cell viability}

Both the CellTiter-Blue and MTT assays were used to calculate viability. The results revealed no significant difference between the two methods of assessment.

The results showed that cell viability reduced significantly in response to exposure to $5 \mu \mathrm{mol} \cdot \mathrm{L}^{-1}$ concentrations of LCA (to $78 \pm 3 \%$ ) and then decreased with $10 \mu \mathrm{mol} \cdot \mathrm{L}^{-1}$ to $46 \pm 3 \%$. This decreased further at $20 \mu \mathrm{mol} \cdot \mathrm{L}^{-1}$ (to $7 \pm 3 \%$ ) (figure $1 \mathrm{a}$ ).

Cell viability was also reduced significantly by DCA at concentration $50 \mu \mathrm{mol} \cdot \mathrm{L}^{-1}(94 \pm 3 \%)$. However, 15 and $30 \mu \mathrm{mol} \cdot \mathrm{L}^{-1}$ DCA did not affect cell viability (figure $1 \mathrm{~b}$ ).

Cell viability also reduced significantly in response to exposure to $50 \mu \mathrm{mol} \cdot \mathrm{L}^{-1}$ concentrations of CA to $88 \pm 3 \%$. This decreased further to the lowest cell viability level at $100 \mu \mathrm{mol} \cdot \mathrm{L}^{-1}(53 \pm 3 \%)$. The lowest concentration (15 and $30 \mu \mathrm{mol} \cdot \mathrm{L}^{-1}$ ) of CA did not affect cell viability (figure $1 \mathrm{c}$ ).

Cell viability was also diminished significantly by CDCA at concentration $50 \mu \mathrm{mol} \cdot \mathrm{L}^{-1}$ to $78 \pm 3 \%$. The cell viability greatly reduced to $100 \mu \mathrm{mol} \cdot \mathrm{L}^{-1}$ of CDCA with $23 \pm 3 \%$. No difference was found in the cell viability at lowest concentration 15 and $30 \mu \mathrm{mol} \cdot \mathrm{L}^{-1}$ compared to control (figure $1 \mathrm{~d}$ ). 

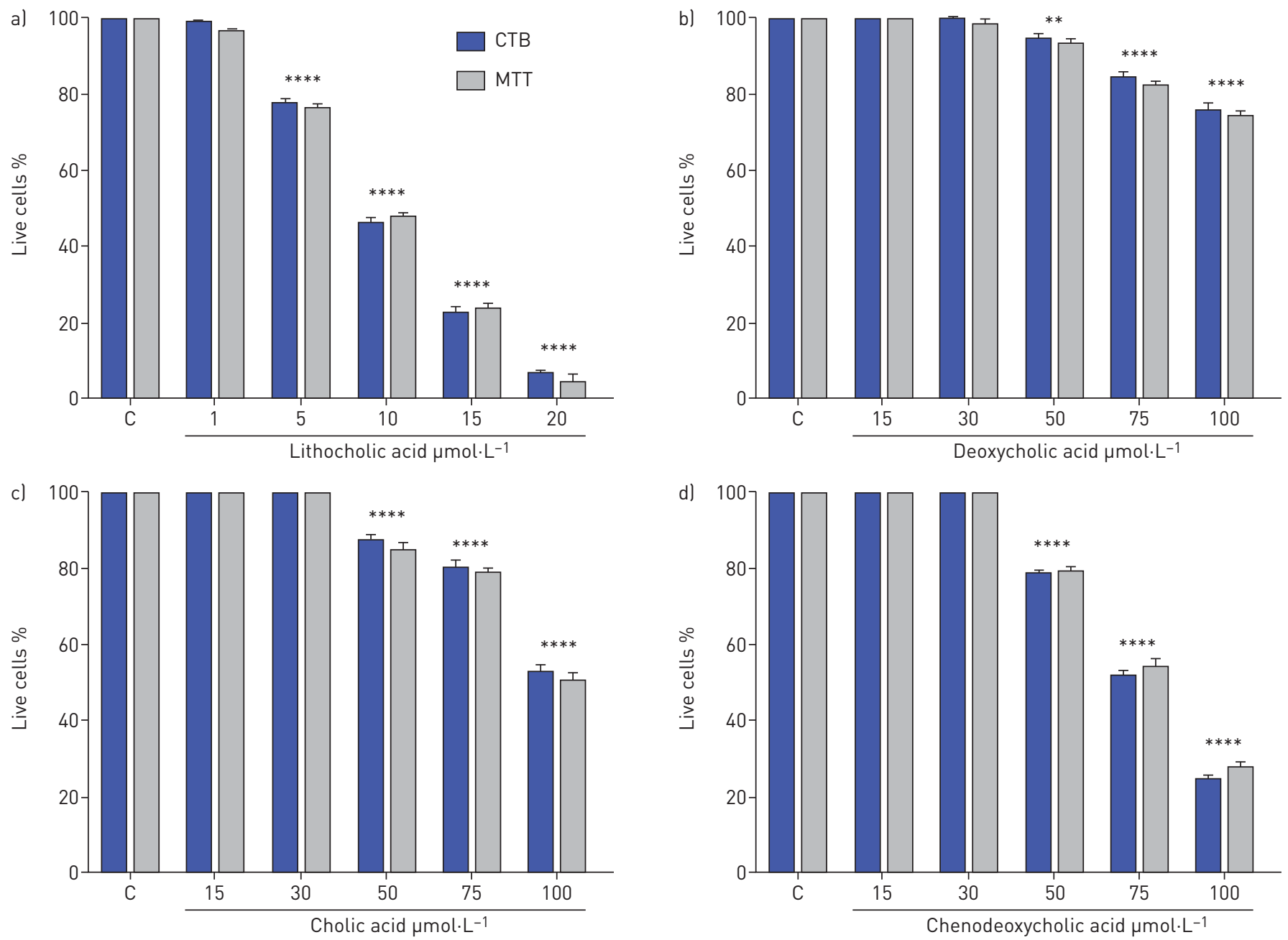

FIGURE 1 Effects of BAs on BEAS-2B cell viability. BEAS-2B cell viability following stimulation with a) lithocholic, b) deoxycholic, c) cholic and d) chenodeoxycholic acids at varying concentrations. Viability is measured as a percentage of vehicle control after $48 \mathrm{~h}$ exposure. Data are presented as mean \pm SEM. Negative controls were measured by fixing the cells in methanol before adding the TiterBlue and MTT reagent ( $n=6$ ). $\mathrm{C}$ : control; CTB: CellTiter-Blue assay; MTT: thiazolyl blue tetrazolium bromide. ${ }^{* *}: \mathrm{p}=0.01 ;{ }^{* * * *}: \mathrm{p}<0.0001$ versus controls.

\section{Release of pro-inflammatory markers by BEAS-2B cells following exposure to BA Lithocholic acid}

IL-8, IL-6 and GM-CSF secretion were all effected in BEAS-2B cells by exposure to lithocholic acid (LCA) at concentrations from 1 to $20 \mu \mathrm{mol} \cdot \mathrm{L}^{-1}$. IL-8 levels increased significantly at $5 \mu \mathrm{mol} \cdot \mathrm{L}^{-1}$ and increased further up to the maximum level at $10 \mu \mathrm{mol} \cdot \mathrm{L}^{-1}$. The level of IL-8 production then fell off at $20 \mu \mathrm{mol} \cdot \mathrm{L}^{-1}$ but was still significantly higher than the control (figure 2a). Moreover, there was a significant increase in IL-6 levels with LCA at concentrations of 10,15 and $20 \mu \mathrm{mol} \cdot \mathrm{L}^{-1}$, but not at 1 and $5 \mu \mathrm{mol} \cdot \mathrm{L}^{-1}$. The result revealed that the highest level of IL-6 production was at $10 \mu \mathrm{mol} \cdot \mathrm{L}^{-1}$ and then declined as the concentration of LCA increased to $20 \mu \mathrm{mol} \cdot \mathrm{L}^{-1}$ (figure $2 \mathrm{~b}$ ). The GM-CSF levels increased significantly at $5 \mu \mathrm{mol} \cdot \mathrm{L}^{-1} \mathrm{LCA}$, and rose further to the maximum level at $10 \mu \mathrm{mol} \cdot \mathrm{L}^{-1}$. The level of GM-CSF production then fell off at $20 \mu \mathrm{mol} \cdot \mathrm{L}^{-1}$ (figure $2 \mathrm{c}$ ).

\section{Deoxycholic acid}

Cells were treated with deoxycholic acid (DCA) at concentrations from 15 to $100 \mu \mathrm{mol} \cdot \mathrm{L}^{-1}$. IL-8 levels increased significantly at $30 \mu \mathrm{mol} \cdot \mathrm{L}^{-1}$ and rose further to the maximum level at $75 \mu \mathrm{mol} \cdot \mathrm{L}^{-1}$. The level of IL-8 production than fell off at $100 \mu \mathrm{mol} \cdot \mathrm{L}^{-1}$ but was still significantly higher than the control. However, no significant increase was observed using concentrations of $15 \mu \mathrm{mol} \cdot \mathrm{L}^{-1} \mathrm{DCA}$ (figure $3 \mathrm{a}$ ). IL-6 levels rose considerably with DCA at concentrations of 50,75 and $100 \mu \mathrm{mol} \cdot \mathrm{L}^{-1}$, but not at 15 and $30 \mu \mathrm{mol} \cdot \mathrm{L}^{-1}$. The highest level of IL-6 secretion was with $100 \mu \mathrm{mol} \cdot \mathrm{L}^{-1}$. The levels reduced to $50 \mu \mathrm{mol} \cdot \mathrm{L}^{-1}$ but remained significantly above the control (figure $3 b$ ). Furthermore, the GM-CSF levels increased significantly at $30 \mu \mathrm{mol} \cdot \mathrm{L}^{-1}$ and increased further up to the maximum level at $75 \mu \mathrm{mol} \cdot \mathrm{L}^{-1}$. The level of GM-CSF production then decreased at $100 \mu \mathrm{mol} \cdot \mathrm{L}^{-1}$ but remained significantly higher than the control. However, no significant increase was observed using a concentration of $15 \mu \mathrm{mol} \cdot \mathrm{L}^{-1}$ DCA (figure $3 \mathrm{c}$ ). 

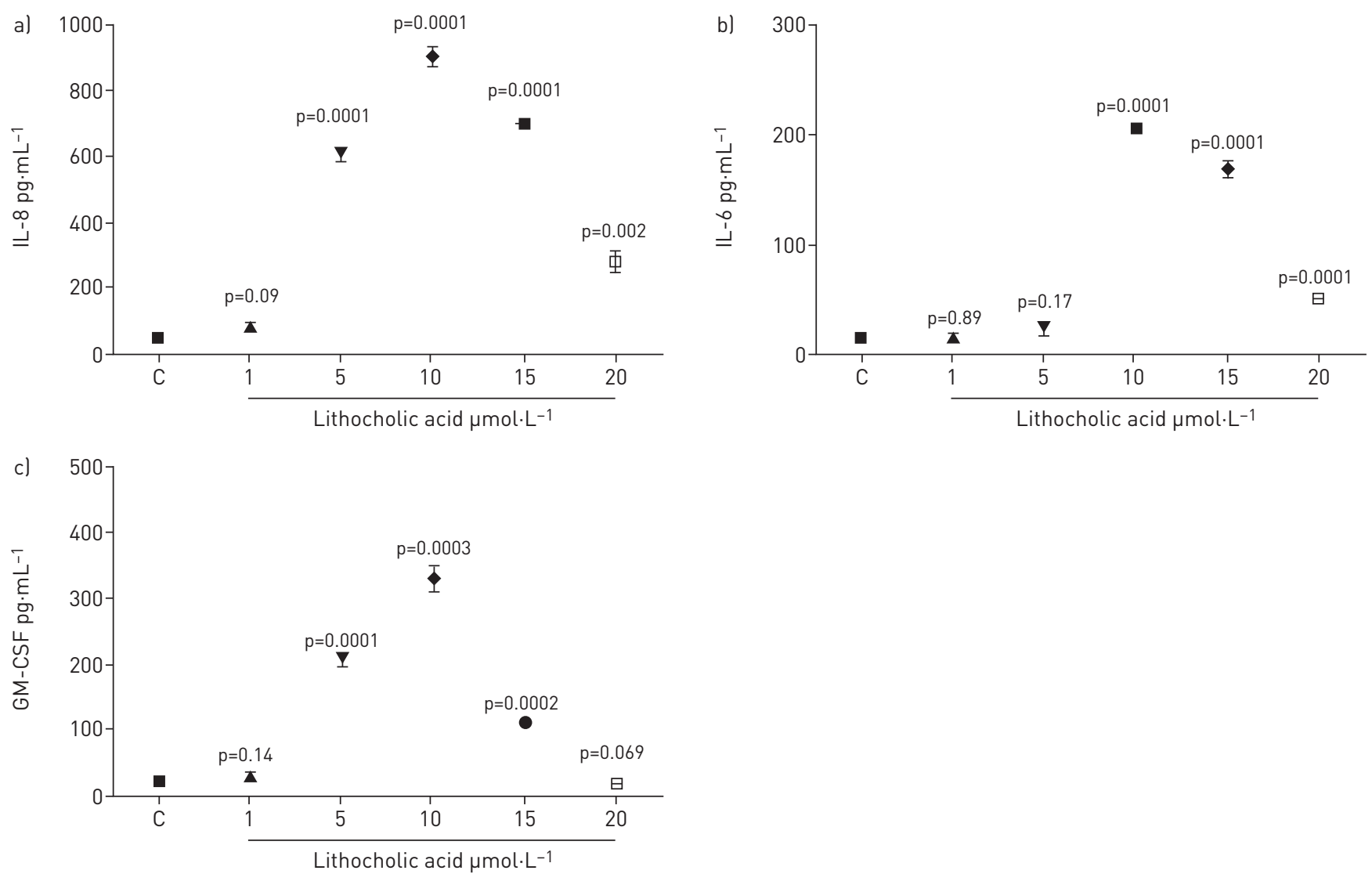

FIGURE 2 Measurement of a) L-8, b) IL-6 and c) GM-CSF release by BEAS-2B cells stimulated with lithocholic acid for $48 \mathrm{~h}$. Data are presented as mean \pm SEM $(n=6)$. ELISA measured cytokine secretion in cell supernatants. Statistical analysis was performed using one-way ANOVA test. p-values of 0.05 or less were regarded as significant. C: control; IL: interleukin; GM-CSF: granulocyte-macrophage colony-stimulating factor.

\section{Cholic acid}

ELISA analysis detected IL-8, IL-6 and GM-CSF in cell culture supernatants following cholic acid (CA) stimulation of BEAS-2B. IL-8 levels increased significantly with CA at concentrations of 50, 75 and $100 \mu \mathrm{mol} \cdot \mathrm{L}^{-1}$, but not at 15 and $30 \mu \mathrm{mol} \cdot \mathrm{L}^{-1}$ (figure $4 \mathrm{a}$ ). The highest level of IL-8 secretion was with $100 \mu \mathrm{mol} \cdot \mathrm{L}^{-1}$. The levels reduced to $50 \mu \mathrm{mol} \cdot \mathrm{L}^{-1}$ but remained considerably above the control. All CA concentrations significantly elevated IL-6 levels except $15 \mu \mathrm{mol} \cdot \mathrm{L}^{-1}$. IL-6 production increased in a dose-dependent manner (figure $4 \mathrm{~b}$ ). Furthermore, the GM-CSF levels increased significantly at $30 \mu \mathrm{mol} \cdot \mathrm{L}^{-1}$ and rose further to the maximum level at $75 \mu \mathrm{mol} \cdot \mathrm{L}^{-1}$. The level of GM-CSF production then dropped at $100 \mu \mathrm{mol} \cdot \mathrm{L}^{-1}$ but was still significantly higher than the control (figure $4 \mathrm{c}$ ).

\section{Chenodeoxycholic acid}

Concentrations of chenodeoxycholic acid (CDCA) from 15 to $100 \mu \mathrm{mol} \cdot \mathrm{L}^{-1}$ were tested. IL- 8 levels increased significantly, but this was not evident at concentrations of $15 \mu \mathrm{mol} \cdot \mathrm{L}^{-1}$ (figure $5 \mathrm{a}$ ). It is clear that IL-8 levels increased significantly at $30 \mu \mathrm{mol} \cdot \mathrm{L}^{-1}$ and rose further to the maximum level at $50 \mu \mathrm{mol} \cdot \mathrm{L}^{-1}$. The level of IL-8 production than fell off at $100 \mu \mathrm{mol} \cdot \mathrm{L}^{-1}$ but was still significantly higher than the control. The IL-6 levels were increased with CDCA at concentrations of 30,50, 75 and $100 \mu \mathrm{mol} \cdot \mathrm{L}^{-1}$, but not at $15 \mu \mathrm{mol} \cdot \mathrm{L}^{-1}$ (figure $5 \mathrm{~b}$ ). The highest level of IL-6 secretion was with $100 \mu \mathrm{mol} \cdot \mathrm{L}^{-1}$. The levels reduced at $30 \mu \mathrm{mol} \cdot \mathrm{L}^{-1}$ but remained significantly above the control. ELISA detected GM-CSF following CDCA stimulation of BEAS-2B cells. The CDCA significantly upregulated GM-CSF production at 30, 50, 75 and $100 \mu \mathrm{mol} \cdot \mathrm{L}^{-1}$ (figure 5c). It was apparent that GM-CSF production increased significantly at $30 \mu \mathrm{mol} \cdot \mathrm{L}^{-1}$ and rose further to a maximum level at $50 \mu \mathrm{mol} \cdot \mathrm{L}^{-1}$. The level of GM-CSF production then decreased at $100 \mu \mathrm{mol} \cdot \mathrm{L}^{-1}$ but was still significantly higher than the control.

\section{Discussion}

Diseases of the lung are a major source of mortality and morbidity worldwide and are becoming increasingly prevalent. Chronic obstructive pulmonary disease (COPD), for example, is the fifth biggest 

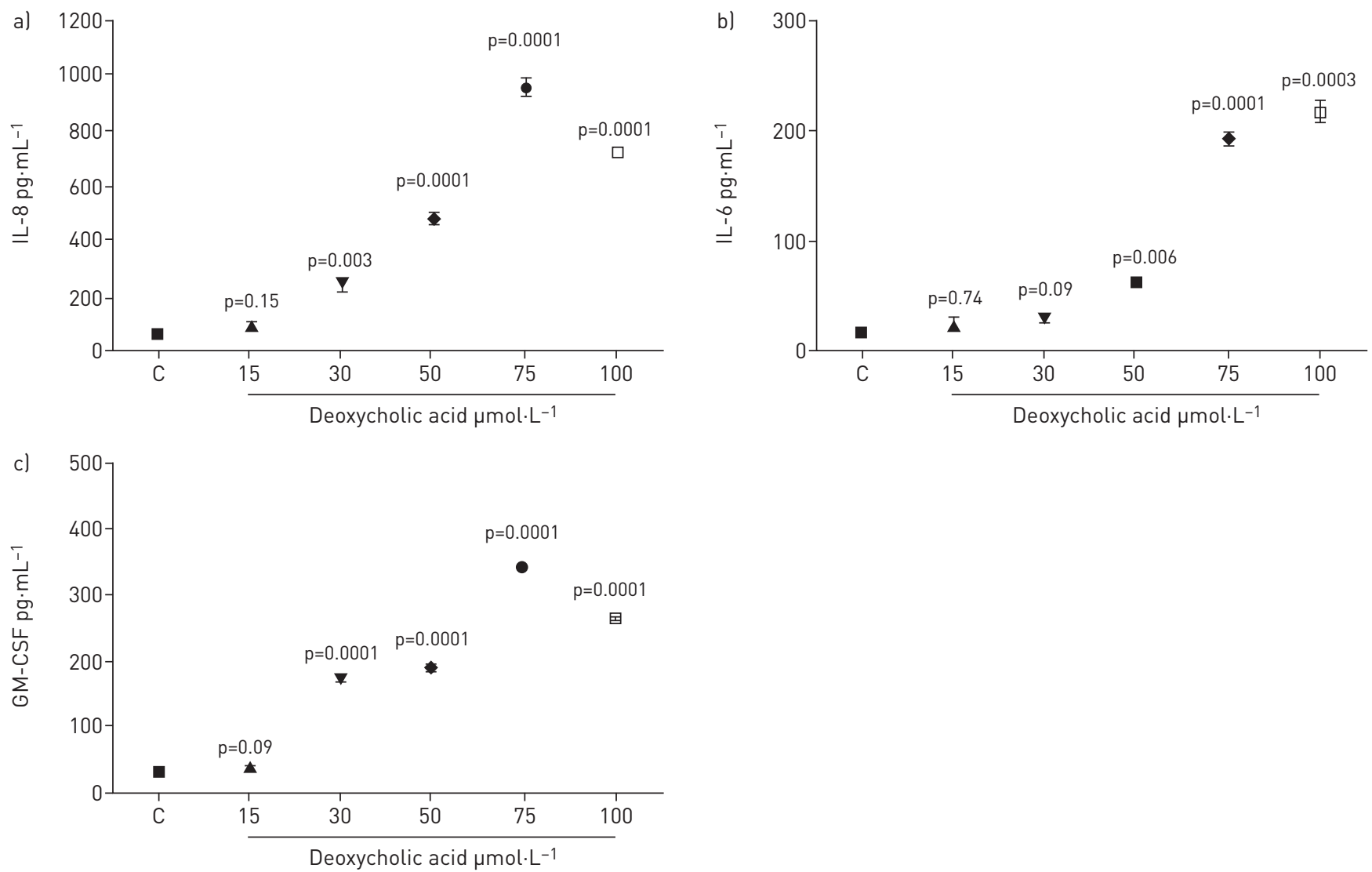

FIGURE 3 Measurement of a) IL-8, b) IL-6 and c) GM-CSF release by BEAS-2B cells stimulated with deoxycholic acid for $48 \mathrm{~h}$. Data are presented as mean \pm SEM $(n=6)$. ELISA measured cytokine secretion in cell supernatants. Statistical analysis was performed using one-way ANOVA test. p-values of 0.05 or less were regarded as significant. C: control; IL: interleukin; GM-CSF: granulocyte-macrophage colony-stimulating factor.

cause of death globally, while cystic fibrosis (CF) and interstitial lung disease are not rare and have a poor prognosis, including low quality of life and premature death. A connection between lung disease and GORD has long been suspected [15, 19] and high incidences of GORD are known to affect sufferers of idiopathic pulmonary fibrosis, asthma, CF and COPD $[20,21]$. It is of interest that in COPD it has been revealed that the second most powerful predictor of exacerbations is a history of heartburn, a symptom associated with GOR [22]. Refluxate from GORD patients has been found to contain BA levels up to a millimolar level [23]. We have previously described high levels of BAs in the lungs of people with CF, both before and after transplantation [13].

The potential role of BAs in respiratory infection and inflammation is becoming increasingly recognised, although the mechanisms are still not well understood. Most BAs in humans exist in their conjugated forms [24]. Treatment for GORD, including the use of PPIs and acid suppression therapies can result in deconjugation of BAs [25], producing a higher ratio of deconjugated to conjugated BAs in patients undergoing GORD treatment [25]. CDCA, DCA and LCA have all been found in their unconjugated forms in airway secretions [26], so their effect may be of particular relevance to patients with GORD.

The effects of both primary and secondary BAs on BEAS-2B viability were studied. Cell viability was found to be affected depending on BA concentration. There was an inverse relationship between BA concentration and measured cell viability, with increasing concentration and decreasing cell viability in a dose-dependent manner. LCA at $5 \mu \mathrm{mol} \cdot \mathrm{L}^{-1}$ caused a decrease in cell viability and $20 \mu \mathrm{mol} \cdot \mathrm{L}^{-1} \mathrm{killed}$ nearly all cells. These results are supported by data provided by Wu et al. [18], whose study exposed human epithelial cells to BAs. The precise mechanism by which BA exposure affects the viability of BEAS-2B cells remains unclear. It is known that cell membranes and cationic permeability are disrupted by BAs in type II pneumocytes in vitro [27], which may provide a mechanistic explanation for our study findings. In vivo, it is possible that this detergent effect may cause mucosal barrier breakdown, disrupting the mucus layer and surfactant function in the lungs, consequently damaging type II pneumocytes, which produce both surfactant protein and phospholipids [27, 28]. 

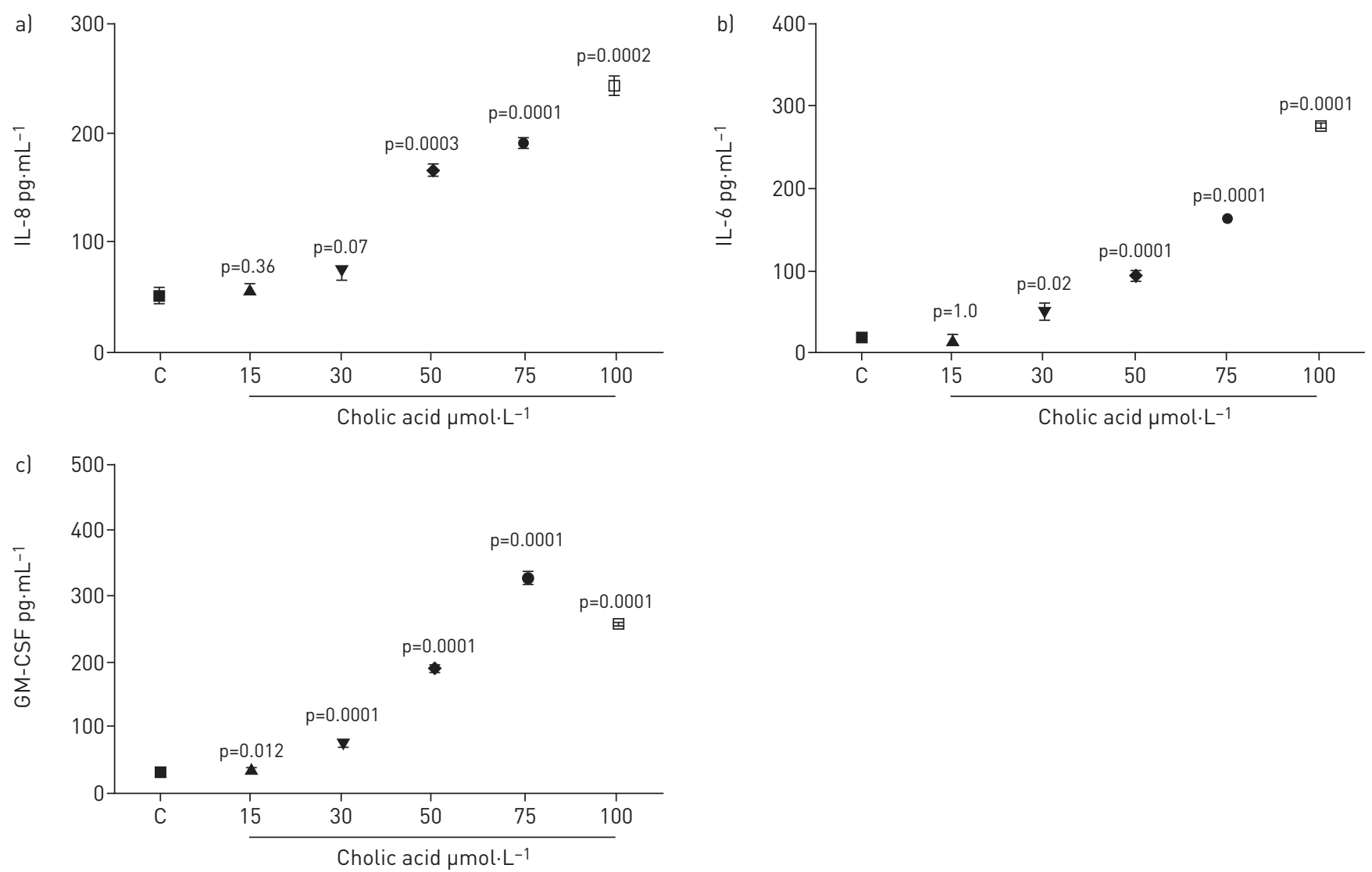

FIGURE 4 Measurement of a) IL-8, b) IL-6 and c) GM-CSF release by BEAS-2B cells stimulated with cholic acid for $48 \mathrm{~h}$. Data are presented as mean \pm SEM $(n=6)$. ELISA measured cytokine secretion in cell supernatants. Statistical analysis was performed using one-way ANOVA test. $p$-values of 0.05 or less were regarded as significant. C: control; IL: interleukin; GM-CSF: granulocyte-macrophage colony-stimulating factor.

BEAS-2B cells retain the morphology of an epithelial cell in vitro [18] and release IL-8 and IL-6 in addition to other cytokines [29]. Under submerged conditions, BEAS-2B cells are commonly used as the in vitro model of human airways epithelium, especially within studies on inhalation toxicity.

Our work demonstrates that cell viability decreased depending on BA concentration. There was a dose response to BA concentration, where increasing levels of BAs were associated with decreased cell viability. Our data demonstrated that low levels of LCA $\left(5 \mu \mathrm{mol} \cdot \mathrm{L}^{-1}\right)$ affected viability and inflammatory cytokine outputs from human bronchial epithelial cells. Moreover, LCA effects occurred at five- to 10-fold lower concentrations compared to the other BAs.

Alongside the potential effect on cell viability, our data show that BA stimulation of epithelial cells is associated with a release of pro-inflammatory cytokines. The study found an increase in the expression of IL-8, IL-6 and GM-CSF following BA challenge.

The lung diseases in which reflux and aspiration are implicated all involve a contribution from acute or chronic inflammation, leading frequently to the use of anti-inflammatory medication, such as steroids [17]. The data gathered in this study support, overall, the hypothesis that BA exposure may have a significant effect on cytokine production and subsequently contribute to airway injury.

IL-8 is a neutrophilic chemoattractant and an angiogenic factor. Immunostaining has been used to identify IL-8 localisation in peribronchial lesions [30]. IL-6 plays a role in the activation of monocytes, T-cell differentiation and B-cell maturation. Moreover, it serves as a pyrogen, inducing fever in response to infection [31]. GM-CSF is involved in macrophage activation and is a strong chemoattractant for neutrophils. It stimulates microbicidal and phagocytotic activity, oxidative metabolism, and improves the cytotoxicity of both macrophages [32] and neutrophils [33]. Increased levels of IL-8, IL-6 and GM-CSF are a common finding in airways and lung disease where reflux and aspiration have been implicated as a possible injury [17, 31, 34].

A strength of our study, which is complementary to the limited amount of previous work available, was that the use of BEAS-2B allowed a comprehensive evaluation of a range of primary and secondary BAs, cytotoxicity and inflammatory cytokine production. This was possible because the available cell numbers did not limit the experiments. 

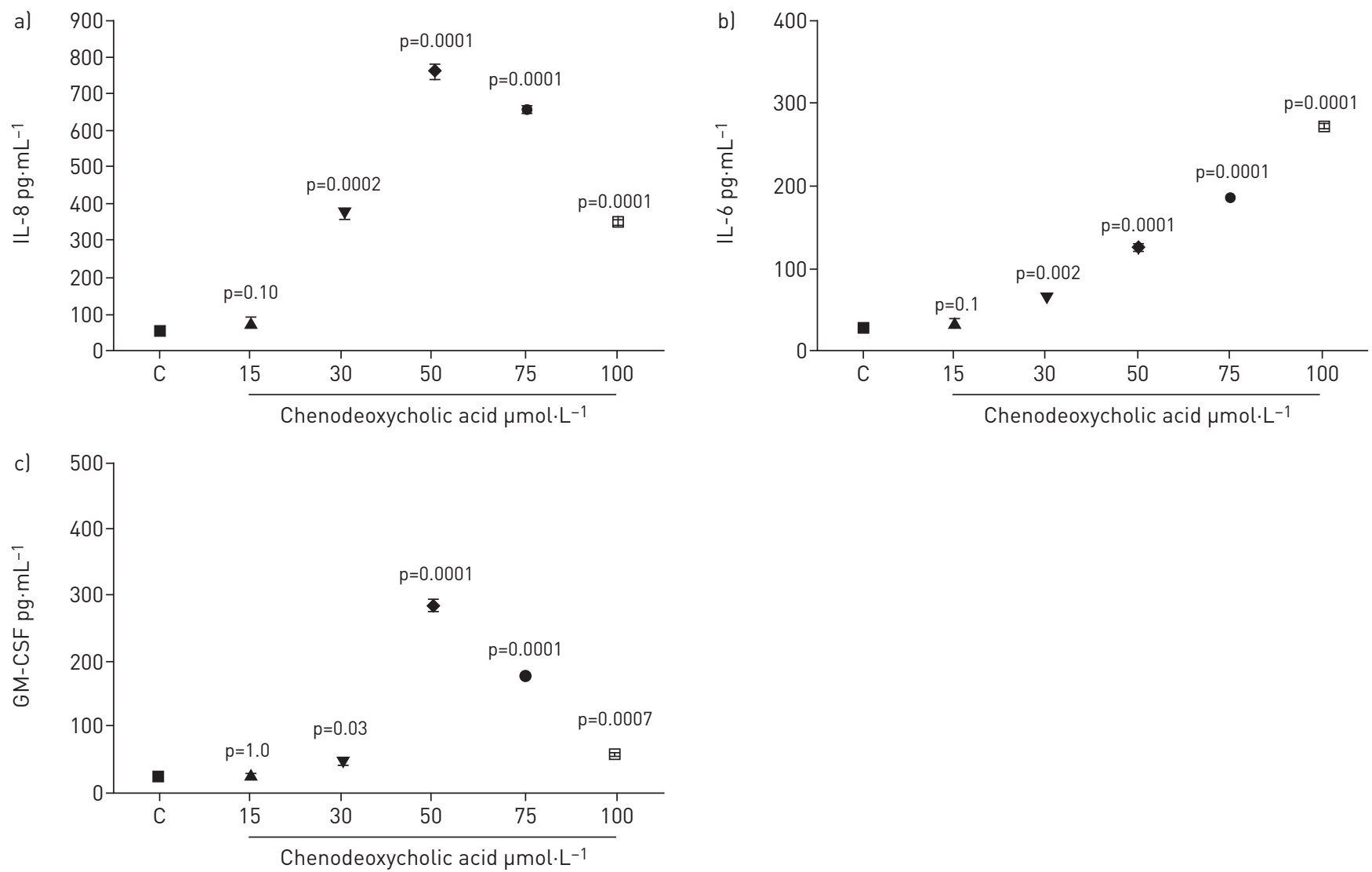

FIGURE 5 Measurement of a) IL-8, b) IL-6 and c) GM-CSF release by BEAS-2B cells stimulated with chenodeoxycholic acid for 48 h. Data are presented as mean \pm SEM $(n=6)$. ELISA measured cytokine secretion in cell supernates. Statistical analysis was performed using one-way ANOVA test. p-values of 0.05 or less were regarded as significant. C: control; IL: interleukin; GM-CSF: granulocyte-macrophage colony-stimulating factor.

Our work could be strengthened by studies involving PBECs. In this study, submerged culture systems were used to examine the association between airways diseases and BAs. Future work could include establishing PBECs at an air-liquid interface, where cells are differentiated into ciliated epithelial cells. The present BA stimulation could then usefully be repeated in in differntiated cells.

\section{Conclusions}

Our model data, revealing cytotoxicity and increased levels of inflammatory cytokines associated with BA stimulation of BEAS-2B epithelial cells, may explain the decreased lung function and chronic inflammation connected with aspiration in respiratory disease patients. These findings and further studies may contribute to an integrated "aerodigestive paradigm" regarding the understanding of reflux-related chronic lung diseases. Increased knowledge in this field may represent an opportunity to consider new approaches to patient therapy.

\section{References}

1 Brown JM, Wilson TM, Metcalfe DD. The mast cell and allergic diseases: role in pathogenesis and implications for therapy. Clin Exp Allergy 2008; 38: 4-18.

2 Todd JL, Palmer SM. Bronchiolitis obliterans syndrome: the final frontier for lung transplantation. Chest 2011; 140: 502-508.

3 Herbella FA, Patti MG. Gastroesophageal reflux disease: from pathophysiology to treatment. World J Gastroenterol 2010; 16: 3745-3749.

4 Fock KM, Ang TL, Bee LC, et al. Proton pump inhibitors. Clin Pharmacokinet 2008; 47: 1-6.

5 Blondeau K, Mertens V, Vanaudenaerde BA, et al. Gastro-oesophageal reflux and gastric aspiration in lung transplant patients with or without chronic rejection. Eur Respir J 2008; 31: 707-713.

6 Patel ARC, Hurst IR. Gastro-oesophageal reflux disease and COPD. In: Rabe KF, Wedzicha JA, Wouters EFM, eds. COPD and Comorbidity (ERS Monograph). Sheffield, European Respiratory Society, 2013; pp. 105-116.

7 McQuaid KR, Laine L, Fennerty MB, et al. Systematic review: the role of bile acids in the pathogenesis of gastro-oesophageal reflux disease and related neoplasia. Aliment Pharmacol Ther 2011; 34: 146-165.

8 Jenkins GJ, Hardie LJ. Bile Acids: Toxicology and Bioactivity. London, Royal Society of Chemistry, 2008.

9 Owen RW, Thompson MH, Hill MJ. Analysis of metabolic profiles of steroids in faeces of healthy subjects undergoing chenodeoxycholic acid treatment by liquid-gel chromatography and gas-liquid chromatography-mass spectrometry. J Steroid Biochem 1984; 21: 593-600. 
10 Turjman N, Nair PP. Nature of tissue-bound lithocholic acid and its implications in the role of bile acids in carcinogenesis. Cancer Res 1981; 41: 3761-3763.

11 Schölmerich J, Becher MS, Schmidt K, et al. Influence of hydroxylation and conjugation of bile salts on their membrane-damaging properties - studies on isolated hepatocytes and lipid membrane vesicles. Hepatology 1984; 4: 661-666.

12 Nasr AO, Robb W, Walsh TN. Duodeno-gastro-esophageal reflux combined and isolated. Am Med J 2013; 4: 127-142.

13 Brodlie M, Aseeri A, Lordan JL, et al. Bile acid aspiration in people with cystic fibrosis before and after lung transplantation. Eur Respir J 2015; 46: 1820-1823.

14 Marik PE. Aspiration pneumonitis and aspiration pneumonia. N Engl J Med 2001; 344: 665-671.

15 Kauer WK, Peters JH, DeMeester TR, et al. Mixed reflux of gastric and duodenal juices is more harmful to the esophagus than gastric juice alone. Ann Surg 1995; 222: 525-531.

16 Stewart CE, Torr EE, Mohd Jamili NH, et al. Evaluation of differentiated human bronchial epithelial cell culture systems for asthma research. J Allergy 2012; 2012: 943982.

17 Mullol J, Baraniuk JN, Logun C, et al. Endothelin-1 induces GM-CSF, IL-6 and IL-8 but not G-CSF release from a human bronchial epithelial cell line (BEAS-2B). Neuropeptides 1996; 30: 551-556.

$18 \mathrm{Wu}$ YC, Hsu PK, Su KC, et al. Bile acid aspiration in suspected ventilator-associated pneumonia. Chest 2009; 13: $118-124$

19 Pearson JEG, Wilson RSE. Diffuse pulmonary fibrosis and hiatus hernia. Thorax 1971; 26: 300-305.

20 Feigelson J, Girault F, Pecau Y. Gastro-oesophageal reflux and esophagitis in cystic fibrosis. Acta Paediatrica 1987; 76: 989-990.

21 Tobin RW, Pope CE, Pellegrini CA, et al. Increased prevalence of gastroesophageal reflux in patients with idiopathic pulmonary fibrosis. Am J Respir Crit Care Med 1998; 158: 1804-1808.

22 Hurst JR, Vestbo J, Anzueto A, et al. Susceptibility to exacerbation in chronic obstructive pulmonary disease. N Engl J Med 2010; 363: 1128-1138.

23 Lefebvre P, Cariou B, Lien F, et al. Role of bile acids and bile acid receptors in metabolic regulation. Physiol Rev 2009; 89: 147-191.

24 Hofmann AF. The continuing importance of bile acids in liver and intestinal disease. Arch Intern Med 1999; 159: $2647-2658$.

25 Theisen J, Nehra D, Citron D, et al. Suppression of gastric acid secretion in patients with gastroesophageal reflux disease results in gastric bacterial overgrowth and deconjugation of bile acids. J Gastrointest Surg 2000; 4: 50-54.

26 Wu Y-C, Hsu P-K, Su K-C, et al. Bile acid aspiration in suspected ventilator-associated pneumonia. Chest 2009; 136: $118-124$.

27 D'Ovidio F, Mura M, Tsang M, et al. Bile acid aspiration and the development of bronchiolitis obliterans after lung transplantation. J Thorac Cardiovasc Surg 2005; 129: 1144-1152.

28 D'Ovidio F, Keshavjee S. Gastroesophageal reflux and lung transplantation. Dis Esophagus 2006; 19: 315-320.

29 Ke Y, Reddel RR, Gerwin BI, et al. Human bronchial epithelial cells with integrated SV40 virus T antigen genes retain the ability to undergo squamous differentiation. Differentiation 1988; 38: 60-66.

30 Zheng L, Walters EH, Ward C, et al. Airway neutrophilia in stable and bronchiolitis obliterans syndrome patients following lung transplantation. Thorax 2000; 55: 53-59.

31 Rincon M, Irvin CG. Role of IL-6 in asthma and other inflammatory pulmonary diseases. Int J Biol Sci 2012; 8: $1281-1290$.

32 Sorgi CA, Rose S, Carlos D, et al. GM-CSF priming drives bone marrow-derived macrophages to a pro-inflammatory pattern and downmodulates PGE 2 in response to TLR2 ligands. PLoS ONE 2012; 7: e40523.

33 Katano $\mathrm{M}$, Okamoto $\mathrm{K}$, Suematsu $\mathrm{N}$, et al. Increased expression of S100 calcium binding protein A8 in GM-CSF-stimulated neutrophils leads to the increased expressions of IL-8 and IL-16. Clin Exp Rheumatol 2010; 29: 768-775.

34 Yamamoto C, Yoneda T, Yoshikawa M, et al. Airway inflammation in COPD assessed by sputum levels of interleukin-8. Chest 1997; 112: 505-510. 